\title{
A neonate with denuded skin: Hay-Wells syndrome
}
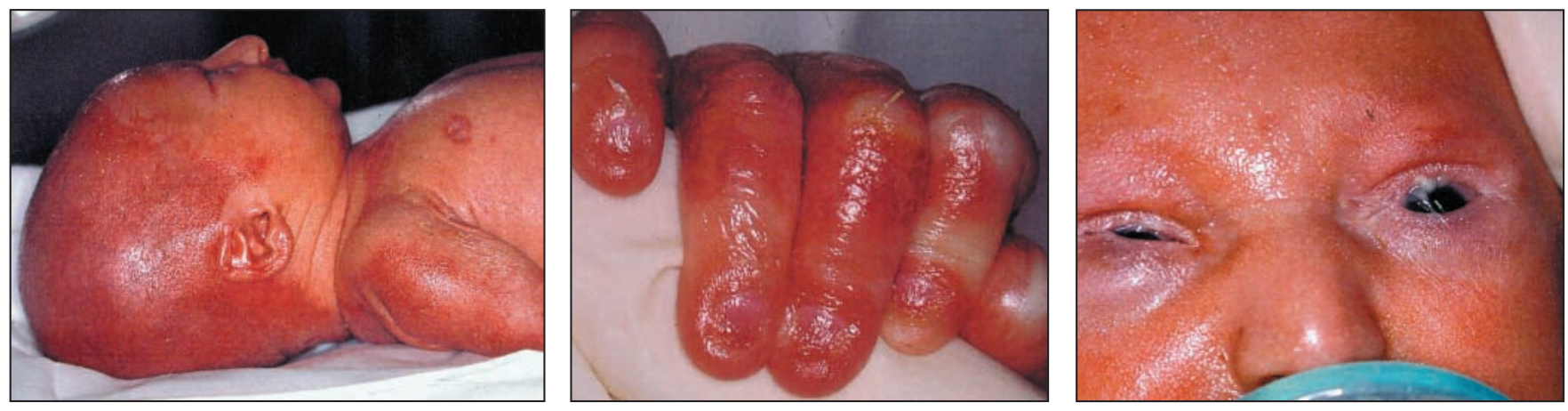

$\mathrm{A}_{\mathrm{b}}^{\mathrm{f}}$ full-term newborn was born with large areas of denuded skin. Her entire scalp was involved, as were her buttocks and the extensor aspects of her arms. Smaller areas of involvement included her abdomen, chest, axilla, groin and legs. Her denuded skin was intensely erythematous and resembled a second-degree burn. Examination of her scalp revealed alopecia with crusting, erythema and scaling (Fig. 1). Her fingernails and toenails were abnormally formed (Fig. 2). Both eyelids were partially fused (ankyloblepharon) with inward turning of the lid margin (entropion), and eyelashes were absent (Fig. 3). A mucous cleft palate was found. The infant's parents were nonconsanguineous, with a healthy 3-year-old child from a previous pregnancy.

The infant remained clinically stable and was immediately placed in an isolette with high humidity. Fluid and broadspectrum antibiotics were administered intravenously and the large denuded areas covered with Vaseline-impregnated gauze dressings. She was transferred to a tertiary pediatric centre, where, on the basis of clinical findings of ankyloblepharon, skin and nail defects, and cleft palate, Hay-Wells syndrome (HWS) was diagnosed. Over the next 4 weeks, the infant experienced multiple episodes of secondary bacterial sepsis, which required intravenous antibiotic therapy and oral analgesic ther- apy. Her eyelid fusions were repaired by simple dissection, and plans were made to repair her mucous cleft palate. Her denuded skin improved spontaneously over several weeks, and she was discharged home at 2 months of age. Only 1 significant skin lesion, in her scalp, remained, which required multiple treatments for recurrent cellulitis over the next 4 months.

HWS was first described in 1976 as an autosomal dominant condition characterized by ankyloblepharon filiforme adnatum, ectodermal dysplasia and cleft palate with or without associated cleft lip. ${ }^{1}$ Ectodermal defects include hair loss, absent or dystrophic nails, pointed and widely spaced teeth and inadequate perspiration (partial anhidrosis). Other associated anomalies include lacrimal duct atresia, supernumerary nipples, syndactyly and auricular deformities. ${ }^{1-3}$

One study has suggested that HWS is caused by heterozygous missense mutations in the p63 gene. ${ }^{3}$ HWS shares some clinical features with ectrodactylyectodermal dysplasia-clefting (EEC) syndrome and with Rapp-Hodgkin syndrome. EEC syndrome is distinguished from HWS by congenital absence of part of the fingers or toes (ectrodactyly), and Rapp-Hodgkin syndrome is distinguished by mid-facial hypoplasia. ${ }^{2}$ Differentiation between HWS and Rapp-Hodgkin syndrome is of- ten difficult, which has led some to suggest that they may represent phenotypic variations of the same entity. ${ }^{4,5}$

Recurrent scalp dermatitis with secondary infection is a common feature of HWS. Management is usually difficult, often requiring aggressive wound care, including surgical débridement and early topical and systemic administration of antibiotics. ${ }^{2}$ Feeding difficulty can be seen during infancy owing to poor oral-motor functions, and a gastrostomy tube may be required to optimize nutritional intake.

\section{Abhay Lodha \\ Clinical fellow \\ Eugene Ng \\ Staff neonatologist \\ Shared Program in Neonatal- \\ Perinatal Medicine \\ University of Toronto \\ Toronto, Ont.}

\section{References}

1. Hay RJ, Wells RS. The syndrome of ankyloblepharon ectodermal defects and cleft lip and palate: an autosomal dominant condition. Br 7 Dermatol 1976;94:227-89.

2. Fosko SW, Stenn KS, Bolognia JL. Ectodermal dysplasia associated with clefting: significance of scalp dermatitis. 7 Am Acad Dermatol 1992;27(20):249-56.

3. McGrath JA, Duijf PH, Doetsch V, Irvine AD, de Waal R, Vanmolkot $\mathrm{KR}$, et al. Hay-Wells syndrome is caused by heterozygous missense mutations in the SAM domain of $\mathrm{p} 63$. Hum Mol Genet 2001;10(3):221-9.

4. Rowan DM. Scalp dermatitis, ectodermal dysplasia and cleft lip and palate: Rapp-Hodgkin or AEC syndrome. Australas 7 Dermatol 1996;37:102-3.

5. Cambiaghi S, Tadini G, Barbaresehi M, Menni S, Caputo R. Rapp-Hodgkin syndrome and AEC syndrome: are they the same entity? $\operatorname{Br} 7$ Dermatol 1994; 130:97-101. 